\title{
O impacto do crédito rural no produto agropecuário brasileiro
}

\author{
The impact of rural credit on brazilian agricultural GDP
}

Murilo José Borges¹ (i), José Luiz Parré ${ }^{10}$

' Programa de Pós-graduação em Ciências Econômicas (PCE), Universidade Estadual de Maringá (UEM), Maringá (PR), Brasil. E-mails: murilo_borges@hotmail.com; jlparre@uem.br

Como citar: Borges, M. J., Parré, J. L. (2022). O impacto do crédito rural no produto agropecuário brasileiro. Revista de Economia e Sociologia Rural, 60(2), e230521. https://doi.org/10.1590/1806-9479.2021.230521

Resumo: O trabalho avalia a relação existente entre crédito rural e produto agropecuário nos anos de 1999 a 2018. Utilizando-se da metodologia de Vetores Autorregressivos, causalidade de Granger e o método dos mínimos quadrados ordinários e generalizados, foram estimados tanto os impactos expressos via elasticidades quanto à relação ótima decorrentes desta relação. Ao longo do período analisado, observouse significativo aumento real do crédito rural, porém tal ampliação ficou limitada a um menor número de estabelecimentos rurais e a contratos com valores mais elevados. A despeito do ambiente de racionamento de crédito rural existente no país, conclui-se que o impacto do crédito rural total sobre o produto agropecuário foi de 0,20\%. Quanto aos testes de causalidade de Granger, os resultados indicam que há precedência temporal do crédito rural ao produto agropecuário e, portanto, de forma unidirecional, o crédito rural causa, no sentido de Granger, PIB agropecuário. Por fim, quanto à relação ótima entre produto agropecuário e crédito rural, o valor estimado de crédito rural que maximiza o produto agropecuário foi de, aproximadamente, $\mathrm{R} \$ 58$ bilhões ao trimestre.

Palavras-chave: crédito rural, PIB Agropecuário.

\begin{abstract}
The paper assesses the relationship between rural credit and agricultural product in the years 1999 to 2018. Using the methodology of autoregressive vectors, Granger causality, and the method of ordinary and generalized least squares, it was possible to estimate the impacts expressed through elasticities and the optimal relationship resulting from this relationship. Over the analyzed period, there was a significant real increase in rural credit; however, this expansion was limited to a lower number of rural establishments and contracts with higher values. Despite the existing rural credit rationing environment in the country, it is concluded that the impact of total rural credit on the agricultural product was $0.20 \%$. As for Granger causality tests, the results indicate that there is temporal precedence of rural credit to the agricultural product and, therefore, in a unidirectional way, rural credit causes, in the sense of Granger, the agricultural GDP. Finally, concerning the optimal relationship between agricultural product and rural credit, the estimated value of rural credit that maximizes agricultural product was approximately $\mathrm{R} \$ 58$ billion per quarter.
\end{abstract}

Keywords: agricultural Credit, Agricultural GDP.

\section{Introdução}

A concessão de crédito rural no Brasil ganhou novo impulso após a estabilização econômica promovida pelo Plano Real. De acordo com Ramos e Martha Junior (2010), a tendência de aumento do crédito rural, iniciada na segunda metade da década de 1990, intensificou-se nos anos 2000. Segundo os dados do Banco Central do Brasil [Bacen] (2019), se em 1999 a relação crédito rural/PIB agropecuário era de aproximadamente 24\%, em 2018, após recessão econômica de 2015 a 2017, chegou a aproximadamente 61\%.

O aumento do crédito rural e a sua importância para a política agrícola se torna ainda mais relevante quando se observam os estudos que evidenciam o impacto positivo do crédito rural sobre as variáveis agropecuárias, tais como: valor da produção, produto agropecuário, produto 
do agronegócio e produtividade total dos fatores (Akram, Hussain, Sabir \& Hussain, 2008; Melo, Marinho \& Silva, 2013; Gasques, Bacchi \& Bastos, 2017). Aliado a isso, há as externalidades positivas inerentes ao setor agropecuário, pois incentivos à agricultura podem gerar um processo de desenvolvimento além da fronteira agropecuária (Taylor, 1994; Chakrabarty, 2003; Geraldine, 2005).

Entretanto, a atividade rural apresenta particularidades que potencializam o problema de assimetria de informação, entre elas as condições climáticas e a heterogeneidade dos agentes. Diante de tal complexidade, é razoável o entendimento de que é necessária a interferência governamental por meio do crédito rural subsidiado (Townsend, 1979; Hoff \& Stiglitz, 1990; Rausser, 1992; Besley, 1994). Apesar dos R $\$ 218$ bilhões disponibilizados na safra 2017-18, o que representa, aproximadamente, $7 \%$ do saldo das operações de crédito de todo sistema financeiro, o crédito rural está restrito a uma pequena parcela dos estabelecimentos rurais do Brasil. De acordo com o Censo Agropecuário 2017, Instituto Brasileiro de Geografia e Estatística [IBGE] (2019), apenas 15,5\% dos estabelecimentos rurais tiveram acesso ao sistema de crédito rural. Entre aqueles que não obtiveram, $42,8 \%$ alegaram motivos não impeditivos para contratação de crédito rural. Tais valores corroboram o paradigma existente nas instituições especializadas de crédito rural (Von Pischke, Heffernan \& Adams, 1981) e, consequentemente, com a hipótese de racionamento de crédito rural no país (Jacob, 2003; Assunção \& Chein, 2007; Carrer, Souza Filho \& Vinholis, 2013).

Portanto, o estudo torna-se relevante ao buscar verificar se a estrutura do mercado de crédito rural, baseada na atuação governamental e escassez, produz efeitos positivos no produto agropecuário do Brasil. Dessa forma, o presente estudo tem como objetivo avaliar a relação existente entre crédito rural e produto agropecuário nos anos de 1999 a 2018. De forma mais específica, procura-se estimar, além do impacto que o crédito rural total e suas modalidades produzem sobre o produto agropecuário, a relação ótima entre produto agropecuário e crédito rural total concedido no Brasil. A escolha deste período se justifica pela estabilização econômica do Brasil e pelas políticas agrícolas implantadas na década de 1990 que foram determinantes para o desenvolvimento da agricultura nos anos subsequentes (Araújo, 2011).

Para tanto, utiliza-se de uma abordagem empírica, fundamentando-se na revisão da legislação, nos trabalhos econométricos relacionados ao objeto de estudo e na metodologia de Vetores Autorregressivos (VAR), causalidade de Granger e no método de mínimos quadrados ordinários (MQO) e mínimos quadrados generalizados (MQG).

A hipótese que rege este estudo é que o crédito rural, mesmo limitado a uma pequena parcela dos estabelecimentos rurais e disponibilizado num volume aquém do nível ótimo capaz de maximizar o produto agropecuário, sugerindo, portanto, um racionamento de crédito rural no Brasil, impacta de forma positiva e unidirecional no produto agropecuário do país.

Compreendem a estrutura deste trabalho, além da presente introdução, três seções e uma conclusão. A primeira seção apresenta as características, a legislação e os principais trabalhos empíricos acerca do tema proposto. Por meio da elaboração de quadros síntese, fez-se uma revisão da literatura empírica acerca dos impactos do crédito rural na atividade econômica. A segunda seção apresenta a base de dados, a metodologia utilizada e os elementos do modelo econométrico. Na terceira seção são apresentados os resultados do modelo e as discussões a partir desse. Por fim, são apresentadas as considerações finais sobre o trabalho. 


\section{Fundamentos e Evidências Empíricas}

\subsection{O Sistema Nacional de Crédito Rural}

Embora a análise dos dados aqui brevemente apresentada se limite aos últimos 20 anos, é relevante informar que a preocupação em estimular o produto agropecuário via concessão de crédito rural já era realizada pelo Banco do Brasil desde a década de 1930 (Bacha, 2018). Já em 1937, foi criada a Carteira de Crédito Agrícola e Industrial (CREAI). No entanto, o marco histórico da política de crédito rural no Brasil ocorreu somente em 1965. Com a criação do Sistema Nacional de Crédito Rural (SNCR), instituído pela Lei n 4.829/1965 (Brasil, 1965), ficou definido que crédito rural é o suprimento de recursos financeiros, por instituições do SNCR para aplicação exclusiva nas finalidades e condições estabelecidas no Manual do Crédito Rural (MCR).

Portanto, ao longo destes mais de 50 anos, o SNCR institucionalizou um modelo, cujo objetivo é fomentar a atividade agropecuária por meio de uma forte atuação estatal, ainda que a partir da década de 1990 a interferência tenha diminuído consideravelmente (Araújo, 2011).

Embora não seja consenso ${ }^{1}$, a atividade rural, pelas suas características, tais como variações climáticas, elevado risco de crédito, sazonalidade de receitas, racionamento de crédito, entre outros, apresenta particularidades que potencializam o problema de assimetria de informação. Que por sua vez, forma-se uma razoável justificativa à interferência governamental por meio de diversos instrumentos de política agrícola, dentre eles o crédito rural subsidiado aos produtores.

De forma mais específica, a atuação governamental na política de crédito rural se dá por meio de instrumentos legais como a equalização das taxas de juros (ETJ); recursos controlados obrigatórios, como exigibilidade sobre depósitos a vista, poupança rural e Letra de Crédito do Agronegócio (LCA); não obrigatórios, como fundos constitucionais; e recursos equalizados pelo governo federal.

Ao longo do período estudado, houve relativa alteração na composição das fontes de recursos. Se nos anos iniciais da série analisada, representada aqui por 1999, aproximadamente $75 \%$ das fontes de recursos eram provenientes dos Recursos Obrigatórios, Poupança Rural e Fundo de Amparo ao Trabalhador (FAT), respectivamente $40,28 \%$ ( $R \$ 4,747$ bilhões), $18,80 \%$ ( $R \$ 2,216$ bilhões) e 16,24\% (R $\$ 1,914$ bilhão), no ano de 2018 essas mesmas fontes representavam aproximadamente $55 \%$, cuja composição é dada por $28,33 \%$ ( $R \$ 51,066$ bilhões) de recursos obrigatórios e $26,62 \%$ ( $\mathrm{R} \$ 48,164$ bilhões) da poupança rural, sem qualquer recurso proveniente do FAT.

Embora as principais fontes de recursos continuem a ser os recursos obrigatórios e a poupança rural, a partir do ano 2010 a composição total dos recursos ficou relativamente menos concentrada com a introdução da LCA e o aumento dos recursos livres. O primeiro ano de registro da fonte LCA foi 2013 e representava apenas 0,002\% (R\$2,642 milhões). Em contrapartida, em 2018 sua participação foi de 15,60\% (R $\$ 28,135$ bilhões).

\subsection{Comportamento do Produto Agropecuário e do Crédito Rural}

A participação da agropecuária na constituição do Produto Interno Bruto (PIB) tem se mantido estável ao longo das últimas décadas. A participação média do PIB agropecuário em relação ao PIB a preços de mercado, valores correntes, foi de 5,48\% no período de 1999 a 2018, Instituto de Pesquisa Econômica Aplicada [Ipeadata] (2019a). Trata-se de participação muito

\footnotetext{
Hoff e Stiglitz (1990) evidenciaram que a intervenção governamental não se mostrou capaz de eliminar as altas taxas de juros cobradas pelo setor privado. Bacen (2005), em seu Relatório de Economia Bancária, apresentou que o direcionamento de crédito para os setores rural e imobiliário gera um efeito de subsídio cruzado de 7,57\% do spread das operações livres, entre os quais 2,55\% são referentes às operações com crédito rural obrigatório.
} 
aquém do que já fora registrado na economia brasileira. Nos anos iniciais da década de 1950, aproximadamente, um quarto do PIB nacional era proveniente da agropecuária.

Entretanto, merece ser destacado que a relevância do setor rural para o PIB nacional vai muito além deste percentual atualmente registrado. Exemplo disso é a metodologia aplicada pelo Centro de Estudos Avançados em Economia Aplicada [Cepea] (2018). Nesta, a participação do PIB do agronegócio no PIB a preços de mercado foi de 21,1\% no ano de 2018 (Centro de Estudos Avançados em Economia Aplicada \& Confederação da Agricultura e Pecuária do Brasil, 2019). Portanto, conclui-se que uma considerada fração do produto brasileiro continua sendo determinada pelo setor primário. Cabe ressaltar ainda que o setor agropecuário exerce papel importante para o crescimento e desenvolvimento econômico: (i)fornecendo alimentos para a população total; (ii) fornecendo capital para a expansão do setor não agrícola; (iii)fornecendo divisas para a compra de insumos e bens de capital estrangeiros necessários ao desenvolvimento de atividades econômicas; (iv)constituindo-se em mercado consumidor para os produtos do setor não agrícola; e (v)fornecendo matéria-prima ao processo de desenvolvimento industrial (Bacha, 2018).

Com relação à taxa de crescimento, entre 1999 e 2018 o PIB agropecuário cresceu em média 2,44\% em termos reais, considerando o índice geral de preços - disponibilidade interna (IGPDI) (Instituto de Pesquisa Econômica Aplicada, 2019b). Enquanto o PIB a preços de mercado, no mesmo período, apresentou crescimento médio de 2,60\% em termos reais. Por outro lado, quando se limita à análise, considerando apenas período recente, mais especificamente a partir de 2011, a taxa de crescimento do produto agropecuário apresentou crescimento real médio superior ao produto nacional, $2,45 \%$ e $1,49 \%$, respectivamente.

Dada a importância relativa do setor agropecuário para a economia brasileira, é importante associar ainda o desempenho do crédito rural ao produto agropecuário. No período de 1999 a 2018, o crédito rural apresentou um crescimento real médio de 7,51\% a.a., considerando o IGP-DI (Instituto de Pesquisa Econômica Aplicada, 2019b). Com o crescimento mais que proporcional do crédito rural em relação ao crescimento do PIB agropecuário, tem-se que a razão crédito rural/PIB agropecuário passou de 24,5\% em 1999 para 61,12\% em 2018, atingindo o máximo no último ano antes da recessão econômica, 2014, quando a razão crédito rural/ PIB agropecuário alcançou 66,58\%.

Para melhor visualização das análises apresentadas, o comportamento do crédito rural, do PIB agropecuário e do PIB a preços de mercado, no período de 1999 a 2018, está agrupado na Figura 1, em que os dados estão representados pelo índice de Laspeyres, ano-base 1999.

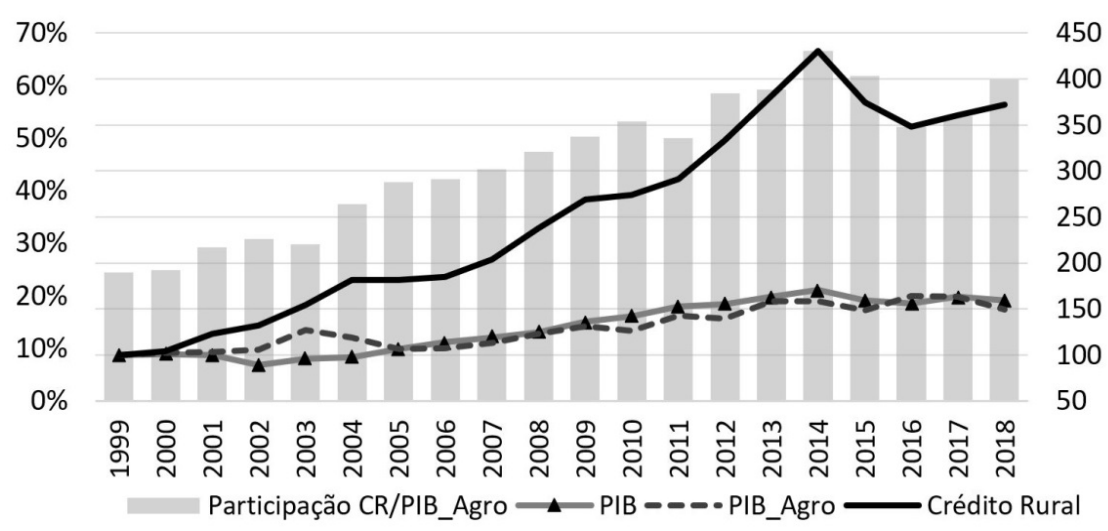

Figura 1 - Participação do crédito rural no PIB Agropecuário e índice de Laspeyres do PIB, PIB Agropecuário e crédito rural (ano-base 1999). Fonte: Anuário Estatístico de Crédito Rural (Banco Central do Brasil, 2019a); Matriz de Dados do Crédito Rural (Banco Central do Brasil, 2019b); e Instituto de Pesquisa Econômica Aplicada (2019a). Nota: Crédito Rural (CR). PIB Agropecuário (PIB_Agro). 
Embora o crédito rural tenha apresentado crescimento bastante significativo quando comparado com o desempenho do produto nacional e agropecuário, ressalta-se que com a recessão econômica, enfrentada pela economia brasileira a partir de 2015, este se mostrou bastante sensível à retração do produto nacional, alcançando nos anos de 2015 e 2016, em relação ao período imediatamente anterior, uma redução acumulada de 21,04\%, evidenciando, portanto, uma política pró-cíclica.

Dado o crescimento do crédito rural, é relevante verificar também o comportamento individual de suas finalidades: custeio, investimento, comercialização e industrialização². De acordo com a figura 2, as finalidades custeio e comercialização não apresentaram maiores oscilações ao longo dos últimos anos, chegando, em 2018, à proporção do total dos recursos de $54,31 \%$ e $16,50 \%$, respectivamente.

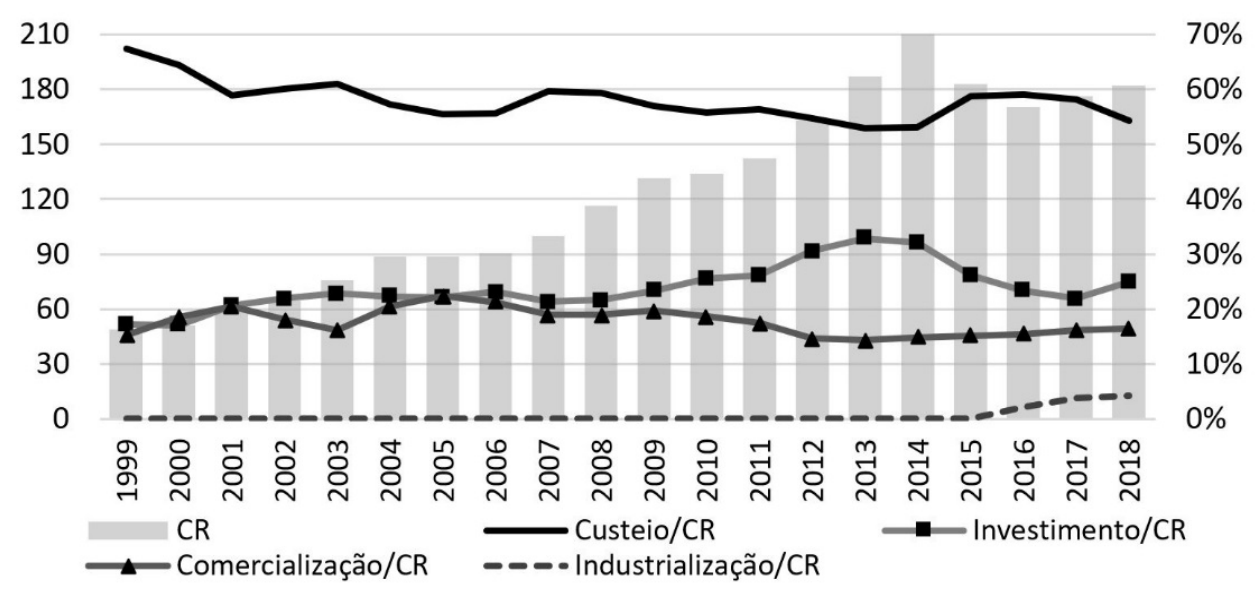

Figura 2 - Crédito rural (valores reais em R\$ bilhões) e suas finalidades (\% recurso total). Fonte: Anuário Estatístico de Crédito Rural (Banco Central do Brasil, 2019a); Matriz de Dados do Crédito Rural

(Banco Central do Brasil, 2019b) e Instituto de Pesquisa Econômica Aplicada (2019a). Nota: Crédito Rural (CR).

Quando se observa mais especificamente, o investimento foi a finalidade que, tanto em valores absolutos quanto em termos dos recursos totais, sofreu maior retração, atingindo 21,92\% (R\$ 35,4 bilhões) em 2017, valor este 33\% inferior ao alcançado em 2014, último ano antes da crise econômica.

Além de evidenciar, conforme mencionado, uma política pró-cíclica, tal resultado mostra não só a profundidade da crise, mas, pior, sua duração. Uma retração do produto agregado como a ocorrida, totalizando 11 trimestres, aumenta as incertezas e a aversão ao risco, que por sua vez posterga investimentos em máquinas, equipamentos e benfeitorias, retroalimentando a recessão econômica.

Em 2017, o total disponibilizado de crédito rural foi de aproximadamente $\mathrm{R} \$ 163,1$ bilhões em termos nominais, em termos reais, considerando o IGP-DI a preços de 2018, esse valor foi de $\mathrm{R} \$ 176,3$ bilhões, para tanto, conforme pode ser visto na tabela 1, foram realizados 1.597.074 contratos, o que resulta no valor médio por contrato de R\$102,3 mil, em termos nominais (Banco Central do Brasil, 2019b).

Nota-se que, aproximadamente, $40 \%$ dos contratos efetuados são de até $\mathrm{R} \$ 10$ mil, que por sua vez não representam $2 \%$ do valor total contratado no referido ano. Por outro lado,

2 Segundo o MCR, as finalidades do crédito rural são caracterizadas conforme a destinação dada aos recursos tomados nas instituições financeiras (Banco Central do Brasil, 2019c). 
contratos acima de $\mathrm{R} \$ 5$ milhões representam, aproximadamente, 0,14\% da quantidade total de contratos e $23 \%$ do valor contratado (Banco Central do Brasil, 2019b).

Merece ser destacado ainda que do total de contratos efetuados em 2017, aproximadamente 65\% correspondem ao Programa Nacional de Fortalecimento da Agricultura Familiar (Pronaf), 1.042.817 contratos. Neste ano, foram disponibilizados pelo Pronaf $R \$ 21,152$ bilhões, resultando no valor médio por contrato de R\$20,2 mil (Banco Central do Brasil, 2019b).

Tabela 1 - Valor médio dos contratos de crédito rural por faixa de valor - 2017 (mil R\$)

\begin{tabular}{cccccc} 
Faixa de Valores & $\begin{array}{c}\text { Qde. } \\
\text { Contratos }\end{array}$ & $\%$ & $\begin{array}{c}\text { Valor } \\
\text { Contratado }\end{array}$ & $\%$ & $\begin{array}{c}\text { Valor Médio } \\
\text { por Contrato }\end{array}$ \\
ATÉ 10,00 & 640.113 & 40,08 & $2.749 .195,60$ & 1,69 & 4,29 \\
10,01 A 20,00 & 242.584 & 15,19 & $3.634 .391,57$ & 2,23 & 14,98 \\
20,01 A 30,00 & 133.473 & 8,36 & $3.340 .582,33$ & 2,05 & 25,02 \\
30,01 A 50,00 & 157.945 & 9,89 & $6.288 .658,58$ & 3,86 & 39,81 \\
50,01 A 100,00 & 177.578 & 11,12 & $13.199 .339,37$ & 8,09 & 74,32 \\
100,01 A 200,00 & 108.856 & 6,82 & $15.508 .420,61$ & 9,51 & 142,46 \\
200,01 A 300,00 & 44.057 & 2,76 & $11.057 .022,28$ & 6,78 & 250,97 \\
300,01 A 500,00 & 43.232 & 2,71 & $16.906 .987,48$ & 10,37 & 391,07 \\
500,01 A 1.000,00 & 30.583 & 1,91 & $21.909 .943,72$ & 13,43 & 716,40 \\
1.000,01 A 2.000,00 & 12.058 & 0,76 & $16.812 .905,11$ & 10,31 & $1.394,33$ \\
2.000,01 A 3.000,00 & 2.748 & 0,17 & $7.035 .766,98$ & 4,31 & $2.560,32$ \\
3.000,01 A 5.000,00 & 1.659 & 0,10 & $6.801 .845,17$ & 4,17 & $4.099,96$ \\
ACIMA DE 5.000,00 & 2.188 & 0,14 & $37.865 .044,28$ & 23,21 & $17.305,77$ \\
Total & $\mathbf{1 . 5 9 7 . 0 7 4}$ & - & $\mathbf{1 6 3 . 1 1 0 . 1 0 3 , 1 6}$ & - & $\mathbf{1 0 2 , 3}$ \\
\hline
\end{tabular}

Fonte: Matriz de Dados do Crédito Rural (Banco Central do Brasil, 2019b).

Dada a importância do crédito rural na política agrícola brasileira, bem como a crescente participação do crédito rural no produto agropecuário do país, os dados dos Censos Agropecuários de 2006 e 2017 mostram que ainda há muito a percorrer quanto à disponibilidade do crédito rural (Instituto Brasileiro de Geografia e Estatística, 2019a, 2019b)

Além da elevada concentração na distribuição do crédito rural evidenciada na tabela 1, a figura 3 apresenta não só uma redução no número de estabelecimentos rurais, mas também uma redução no número de estabelecimentos rurais que obtiveram alguma forma de financiamento rural.

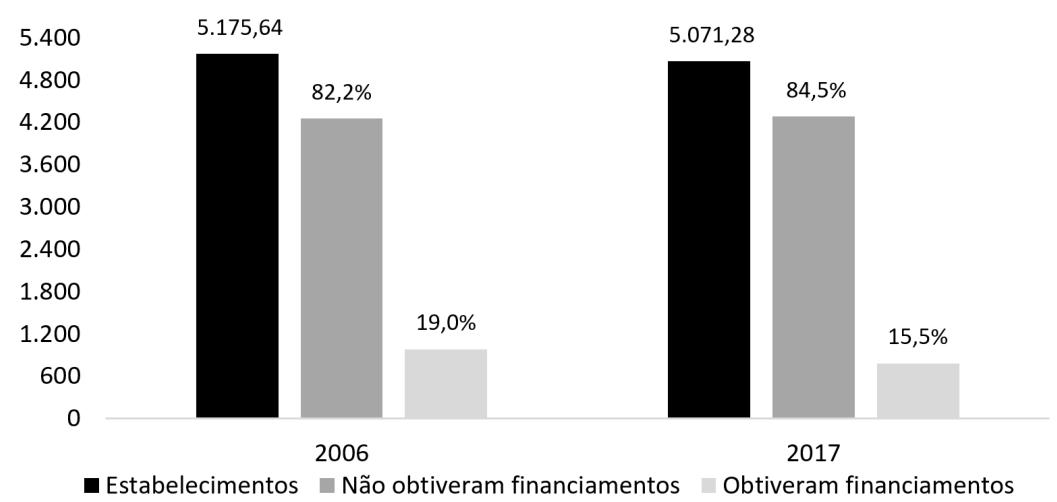

Figura 3 - Número de Estabelecimentos Rurais (mil) e o Financiamento Rural (\%). Fonte: Censo Agropecuário 2006 (Instituto Brasileiro de Geografia e Estatística, 2019a) e Censo Agropecuário 2017 (Instituto Brasileiro de Geografia e Estatística, 2019b). 
Em 2017, foram estimados, aproximadamente, 5,071 milhões de estabelecimentos rurais, o que representa uma redução de $2 \%$ frente ao número registrado em 2006. Desse total, apenas $15,5 \%$ dos estabelecimentos rurais obtiveram financiamento via crédito rural, uma redução de $18 \%$ frente os estabelecimentos com financiamento em 2006 (19\%).

Por fim, como pode ser visualizado na Figura 4, dos estabelecimentos rurais que não obtiveram financiamento em 2017, 4.287.050, mais da metade deles, 2.208.930, alegou que não precisou de nenhuma modalidade de financiamento rural. Porém, é possível notar que, eliminando os motivos que são impeditivos para obtenção de qualquer modalidade de crédito rural, ou seja, inadimplência e falta de garantia, há aproximadamente 1.834 .470 estabelecimentos rurais (42,8\%) que não obtiveram financiamento rural por motivos não impeditivos, tais como burocracia, desconhecimento ou medo de contratar alguma modalidade de crédito rural.

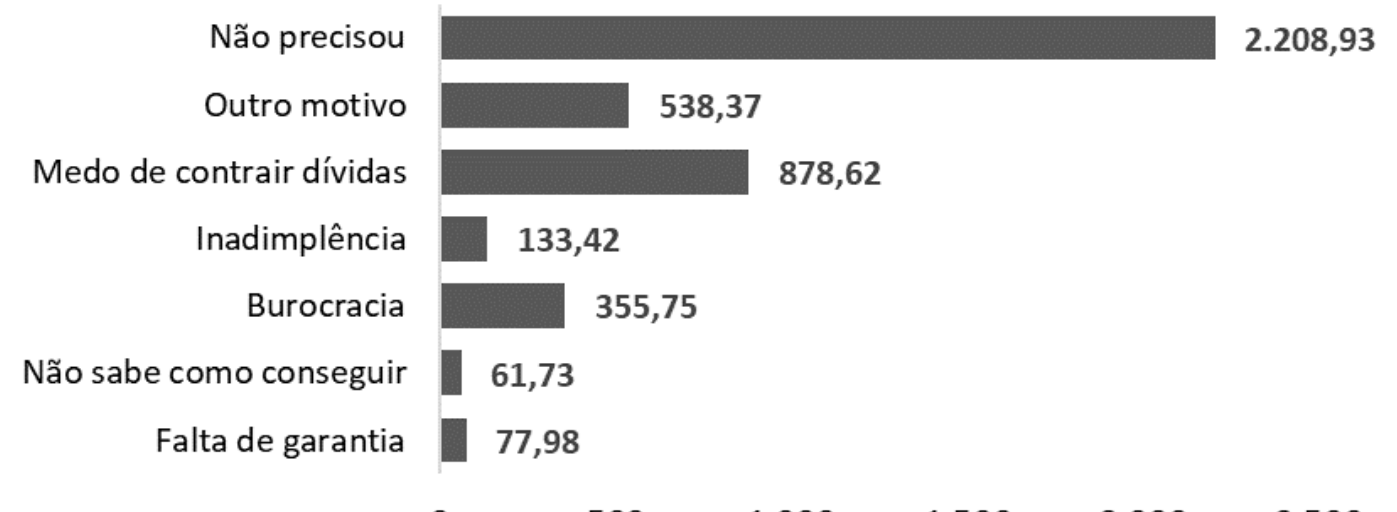

Figura 4 - Estabelecimentos sem Financiamento: motivo da não obtenção (mil). Fonte: Censo Agropecuário 2017 (Instituto Brasileiro de Geografia e Estatística, 2019b).

Nota-se, portanto, que nas últimas décadas a participação do PIB agropecuário no PIB a preços correntes manteve-se praticamente constante, porém com participação mais intensa do crédito rural como instrumento de política agrícola.

Entretanto, nota-se que a ampliação real do crédito rural ocorreu de forma descentralizada e limitada. Descentralizada porque houve melhor distribuição dos recursos tanto nas fontes de financiamento quanto nas suas finalidades. Por outro lado, se deu de forma limitada devido à menor cobertura de estabelecimentos rurais com acesso ao crédito rural e maior concentração de crédito rural em contratos de valores mais elevados.

De qualquer forma, os dados evidenciam que, ao menos pelo lado da demanda, há espaço para ampliação do crédito rural, pois, além da razoável parcela dos estabelecimentos rurais que não obtiveram financiamentos por motivos não impeditivos, é majoritário o entendimento de que há racionamento de crédito para atividade rural.

Stiglitz e Weiss (1981) evidenciam que o mercado de crédito, no sentido amplo, apresenta tendência ao racionamento, dado que a assimetria de informação e a seleção adversa são fatores responsáveis por esse racionamento. Se o credor elevar a taxa de juros para mitigar seu risco, acabará selecionando somente aqueles dispostos a aceitar taxas de juros mais elevadas, geralmente devedores mais propensos ao risco de crédito.

Mais especificamente quanto ao mercado de crédito rural, Von Pischke et al. (1981) afirmam que há um paradigma inerente às instituições especializadas de crédito rural. Isso ocorre, inicialmente, graças a um entendimento político dominante de que dada a falta de serviços 
financeiros rurais se faz necessária a concessão de crédito rural subsidiado. Entretanto, a incapacidade de mobilizar poupança e a assimetria de informação geram dificuldades que resultam em grandes quantidades de crédito concentradas nas mãos de relativamente poucos agentes, ou, então, amplamente distribuídas em pequenas quantias por razões políticas. 0 resultado desse processo é a disseminação de inadimplência, desvio de recursos do empréstimo para fins não especificados nos contratos de empréstimo e fraude por parte dos tomadores.

Aliado a isso, Yaron (1992) expõe que, entre outras razões, o racionamento de crédito rural [e sua concentração] se dá pelo fato de que as instituições financeiras envolvidas, limitadas por taxas de juros máximas impostas legalmente, buscam maximizar o retorno sobre suas carteiras de empréstimos rurais. Logo, na tentativa de minimizar o risco e os custos administrativos envolvidos, favorecem os grandes tomadores de empréstimos, excluindo, assim, os pequenos empreendedores.

O racionamento e a concentração de crédito rural também são evidenciados por Guanziroli (2019). Neste estudo, o referido autor faz uma compilação e análise de 35 avaliações feitas na última década sobre o Pronaf e divulgadas pela Sober (Sociedade Brasileira de Economia, Administração e Sociologia Rural). Entre os resultados encontrados, conclui-se que o subsídio ao crédito permite que ele seja "colonizado" por quem oferece maiores garantias, geralmente grandes proprietários, aumentando a utilização de técnicas de capital intensivo, que não geram emprego, e não estimula a poupança rural. Dessa forma, Guanziroli (2019) questiona se o crédito rural subsidiado é a via mais eficiente para amparar a agricultura familiar.

De outra forma, Carrer et al. (2013) definem que o racionamento de crédito rural é dado pelo limite máximo de recursos por produtor, caracterizando-se mais como um racionamento extensivo de crédito. Contudo, para contornar os limites máximos de obtenção de recursos oficiais, os agentes agropecuários podem adotar estratégias que combinem a utilização de recursos controlados do crédito rural oficial com a utilização de recursos a taxas de juros determinadas pelo mercado, i.e., recursos não controlados.

Importante destacar que, embora os recursos não controlados tenham ganhado importância relativa a partir de 2010, estes ainda representam pequena parcela do volume total de crédito disponibilizado. Em 2018, 12,3\% das fontes de recursos eram provenientes das fontes não controladas, das quais $38 \%$ eram de recursos livres, $37 \%$ de LCA livre e $24 \%$ de poupança rural livre (Banco Central do Brasil, 2019b).

Portanto, o financiamento via bancos no Brasil com recursos não controlados não desempenha um papel central no cenário de desenvolvimento econômico, pois os bancos, sobretudo os privados, são inclinados à realização de operações com alta rentabilidade e baixo risco de crédito, acarretando racionamento de crédito principalmente para segmentos mais complexos como o agropecuário (Jacob, 2003).

\subsection{Síntese da Literatura Econométrica}

Para concluir esta seção, elaborou-se o quadro 1, que apresenta um breve resumo da literatura empírica acerca dos impactos produzidos pelo crédito rural, que por sua vez serviram de inspiração para o presente estudo.

De forma geral, os trabalhos pesquisados apontam efeitos positivos do crédito rural sobre diversas variáveis econômicas. Destaque para o trabalho de Castro \& Teixeira (2004), evidenciando que a ETJ possui justificativa econômica, uma vez que os benefícios gerados na forma de crescimento econômico mais que compensam os gastos com a política. 
Quadro 1 - Estudos empíricos selecionados sobre o crédito rural

\begin{tabular}{|c|c|c|c|}
\hline $\begin{array}{l}\text { Autores } \\
\text { (ano), País } \\
\text { e Período }\end{array}$ & Variáveis & Método & Principais Resultados \\
\hline $\begin{array}{l}\text { Castro \& } \\
\text { Teixeira } \\
(2004), \\
\text { Brasil, } 1995\end{array}$ & $\begin{array}{l}\text { Produção do setor consumida } \\
\text { pelas famílias, governo, } \\
\text { destinada ao investimento, } \\
\text { ao exterior e utilizada como } \\
\text { consumo intermediário; } \\
\text { demanda final; VBP; custo da } \\
\text { produção; importação; valor } \\
\text { adicionado; remuneração } \\
\text { do trabalho, do capital; valor } \\
\text { dos impostos e número de } \\
\text { setores produtivos. }\end{array}$ & $\mathrm{MIP}^{1}$ & $\begin{array}{l}\text { Para cada real gasto com a equalização } \\
\text { das taxas de juros (ETJ) gera um } \\
\text { crescimento no PIB equivalente a 1,75 } \\
\text { vez o montante gasto com a ETJ, para } \\
\text { a agricultura familiar, e } 3,57 \text { vezes } \\
\text { o gasto com a ETJ para a agricultura } \\
\text { comercial. Além disso, ocorre aumento } \\
\text { da arrecadação de impostos de } 16,9 \% \\
\text { do gasto com a ETJ, para a agricultura } \\
\text { familiar, e } 37 \% \text { do gasto com a ETJ para a } \\
\text { agricultura comercial. }\end{array}$ \\
\hline $\begin{array}{l}\text { Akram et al. } \\
\text { (2008), } \\
\text { Paquistão, } \\
1973 \text { a } 2005\end{array}$ & $\begin{array}{l}\text { PIB; PIB agrícola; crédito } \\
\text { agrícola; disponibilidade } \\
\text { de água; número de poços } \\
\text { tubulares; número de } \\
\text { tratores; semente; pobreza; e } \\
\text { pobreza rural. }\end{array}$ & $\mathrm{ECM}^{2}$ & $\begin{array}{l}\text { A elasticidade de curto prazo do } \\
\text { crédito agrícola em relação ao PIB foi } \\
\text { de } 0,03 \text { e a de longa foi de } 0,16 \text {. Já a } \\
\text { elasticidade de curto prazo do crédito } \\
\text { agrícola em relação ao PIB agrícola } \\
\text { foi de } 0,13 \text {. Os resultados explicaram } \\
\text { ainda a elasticidade do crédito } \\
\text { agrícola em relação à pobreza -0,35\% } \\
\text { e - } 0,27 \% \text { no curto prazo e longo prazo, } \\
\text { respectivamente. }\end{array}$ \\
\hline $\begin{array}{l}\text { Melo et al. } \\
\text { (2013), } \\
\text { Brasil, 1995 } \\
\quad \text { a } 2009\end{array}$ & $\begin{array}{l}\text { PIB real agropecuário; Selic, } \\
\text { INPC; crédito rural total; } \\
\text { crédito rural agricultura; } \\
\text { crédito rural pecuária; e } \\
\text { crédito rural por finalidade. }\end{array}$ & $\begin{array}{l}\mathrm{VEC}^{3} \mathrm{e} \\
\text { Causalidade } \\
\text { de Granger }\end{array}$ & $\begin{array}{l}\text { Um choque de } 1,9 \% \text { na proporção } \\
\text { de crédito rural gera um impacto de } \\
0,79 \% \text { no PIB agropecuário. Relação de } \\
\text { causalidade de Granger bidirecional entre } \\
\text { crédito rural e PIB real agropecuário. } \\
\text { A relação de causalidade de Granger } \\
\text { depende do componente do crédito } \\
\text { rural. }\end{array}$ \\
\hline $\begin{array}{l}\text { Moura } \\
(2016), \\
\text { Brasil, } 1969 \\
\text { a } 2014\end{array}$ & $\begin{array}{l}\text { PIB do setor agropecuário, } \\
\text { taxa de crescimento do PIB } \\
\text { agropecuário, crédito rural } \\
\text { total concedido, razão entre o } \\
\text { crédito rural total concedido } \\
\text { e o PIB agropecuário, número } \\
\text { de máquinas agrícolas } \\
\text { vendidas no ano, deflator } \\
\text { implícito do PIB agropecuário } \\
\text { e razão entre o valor das } \\
\text { exportações agropecuárias e } \\
\text { o PIB agropecuário; }\end{array}$ & $\begin{array}{l}\text { VAR, } \\
\text { FMOLS }^{4} \\
\text { ARDL }^{5}\end{array}$ & $\begin{array}{l}\text { Impacto positivo e presença uniforme } \\
\text { de causalidade unidirecional do crédito } \\
\text { rural para o crescimento do produto } \\
\text { agropecuário. }\end{array}$ \\
\hline $\begin{array}{l}\text { Gasques et al. } \\
\text { (2017), } \\
\text { Brasil, } 1996 \\
\text { a } 2015\end{array}$ & $\begin{array}{l}\text { Valor bruto de produção } \\
\text { agropecuário (VBP); PIB } \\
\text { da agropecuária; PIB do } \\
\text { agronegócio; produtividade } \\
\text { total dos fatores (PTF); e } \\
\text { crédito rural. }\end{array}$ & VAR e VEC & $\begin{array}{l}\text { Crédito sobre o VBP, com impacto de } \\
0,40 \% \text { para o aumento de } 1,0 \% \text { do crédito } \\
\text { rural; crédito sobre o PIB do agronegócio, } \\
\text { com impacto de } 0,19 \% \text { para o aumento } \\
\text { de } 1,0 \% \text { do crédito rural; crédito sobre } \\
\text { o PIB da agropecuária, com impacto } \\
\text { de } 0,18 \% \text {; e crédito sobre a PTF, com } \\
\text { impacto de } 0,12 \% \text {. }\end{array}$ \\
\hline
\end{tabular}

Fonte: elaboração própria. Nota: ${ }^{1}$ Matriz Insumo Produto (MIP). ${ }^{2}$ Modelo com Correção de Erros (ECM). ${ }^{3}$ Autoregressão Vetorial com Correção de Erros (VEC). ${ }^{4}$ Fully Modified Ordinary Least Squares (FMOLS). ${ }^{5}$ Modelo Autorregressivo com Defasagens Distribuídas (ARDL).

O estudo de Moura (2016) evidencia a presença de causalidade, no sentido de Granger, de forma unidirecional, no sentido do crédito rural para o crescimento econômico. Segundo Akram et al. (2008), além do impacto positivo que o crédito rural gera sobre o PIB agrícola na 
economia paquistanesa, este ainda tem uma relação negativa com a pobreza, evidenciando que um aumento de $1 \%$ no volume de crédito rural disponibilizado provoca redução de $0,35 \%$ na pobreza.

Por sua vez, o estudo desenvolvido por Melo et al. (2013), utilizando-se da metodologia VAR, concluiu que um choque de $+1,9 \%$ na proporção de crédito rural gerou um impacto de $+0,79 \%$ no PIB agropecuário.

No mesmo sentido, o trabalho de Gasques et al. (2017) apresentou os impactos positivos do crédito rural sobre o VBP, PIB agropecuário, PIB agronegócio e PTF. Neste estudo, especificamente quanto ao produto agropecuário, evidenciou-se que uma variação de $1 \%$ no crédito rural causa uma variação positiva de $0,18 \%$ no PIB agropecuário.

\section{Base de dados e Metodologia}

\subsection{Base de Dados}

Para a elaboração da base de dados foram utilizadas séries extraídas do Bacen (Anuário Estatístico do Crédito Rural e Matriz de Dados do Crédito Rural) e IBGE (Contas Nacionais Trimestrais). As séries têm periodicidade trimestral, abrangendo o período de 1999 a 2018, totalizando 80 observações. A escolha deste período se justifica pela estabilização econômica ocorrida no Brasil e pelas políticas agrícolas implantadas ao longo da década 1990 e que foram determinantes para o desenvolvimento da agricultura, principalmente nos últimos anos da referida década.

Destaca-se que a década de 1990, em particular 1997, marca um ponto chamado de quebra estrutural, a partir do qual a produtividade [do setor agropecuário] passa a crescer num ritmo maior do que vinha crescendo até então (GASQUES et al., p. 134, 2017).

Para estimação das elasticidades, optou-se como proxy para o produto rural o PIB agropecuário em termos reais corrigido pelo IGP-DI (PIB_AGRO), sendo esta a variável dependente das regressões simples a serem estimadas. As variáveis independentes utilizadas serão o crédito rural total $\left(C R_{-} T O T\right)$, crédito rural finalidade custeio $\left(C R_{-} C U S T\right)$, crédito rural finalidade investimento $\left(C R_{-} I N V\right)$ e crédito rural finalidade comercialização $\left(C R \_C O M E R\right)$. Espera-se que tanto o crédito rural total quanto o crédito rural segregado por finalidade apresentem, em suas respectivas regressões simples, impactos positivos no PIB agropecuário. Outras variáveis agropecuárias poderiam ser utilizadas como proxies para o produto rural, como o VBP e o PIB agronegócio, no entanto essas variáveis têm periodicidade anual e estão limitadas a pequenas amostras.

Cabe ressaltar ainda que outras variáveis, tais como condições edafoclimáticas e preços agrícolas, influenciam tanto na decisão de plantio como no tamanho das colheitas e, consequentemente, determinam o produto agropecuário. É evidente, portanto, que o produto agropecuário dependa de outras variáveis e não somente o crédito rural.

No entanto, é importante destacar que o presente estudo se propõe a avaliar, por meio de metodologia robusta, a relação existente entre crédito rural e produto agropecuário. Logo, não faz parte do escopo deste estudo selecionar e analisar outras variáveis explicativas para determinação da produção agrícola.

Além disso, modelos de regressão múltipla exigem maior disponibilidade de dados e graus de liberdade, que por vezes limitam a pesquisa, pois diversas variáveis são encontradas apenas na periodicidade anual. Nesse sentido, conforme utilizado no estudo de Gasques et al. (2017), para efeito dos impactos do crédito rural sobre o PIB agropecuário, a metodologia empregada 
considera que os efeitos dessas variáveis não incluídas no modelo sejam representados pelos termos autorregressivos, ou seja, os efeitos estão sendo captados pelo passado histórico da série de interesse.

Portanto, é razoável supor que o fato de haver variáveis explicativas omitidas não invalida a busca pela melhor compreensão da relação entre o principal instrumento de política agrícola no Brasil, crédito rural, e o produto agropecuário, desde que, é claro, seja empregada metodologia que minimize eventuais limitações existentes no modelo proposto.

Para efeitos de padronização e redução da dispersão dos dados, as séries foram ajustadas com os valores transformados em logaritmos, de forma que os coeficientes estimados são analisados como a própria elasticidade. As séries ainda foram dessazonalizadas pelo método multiplicativo X12 ARIMA (Findley et al., 1998). Pode-se observar na figura 5 que as séries padronizadas e dessazonalizadas possuem clara tendência de alta até o ano de 2014, após o referido ano todas as séries apresentaram retração ou relativa estacionariedade 3 .
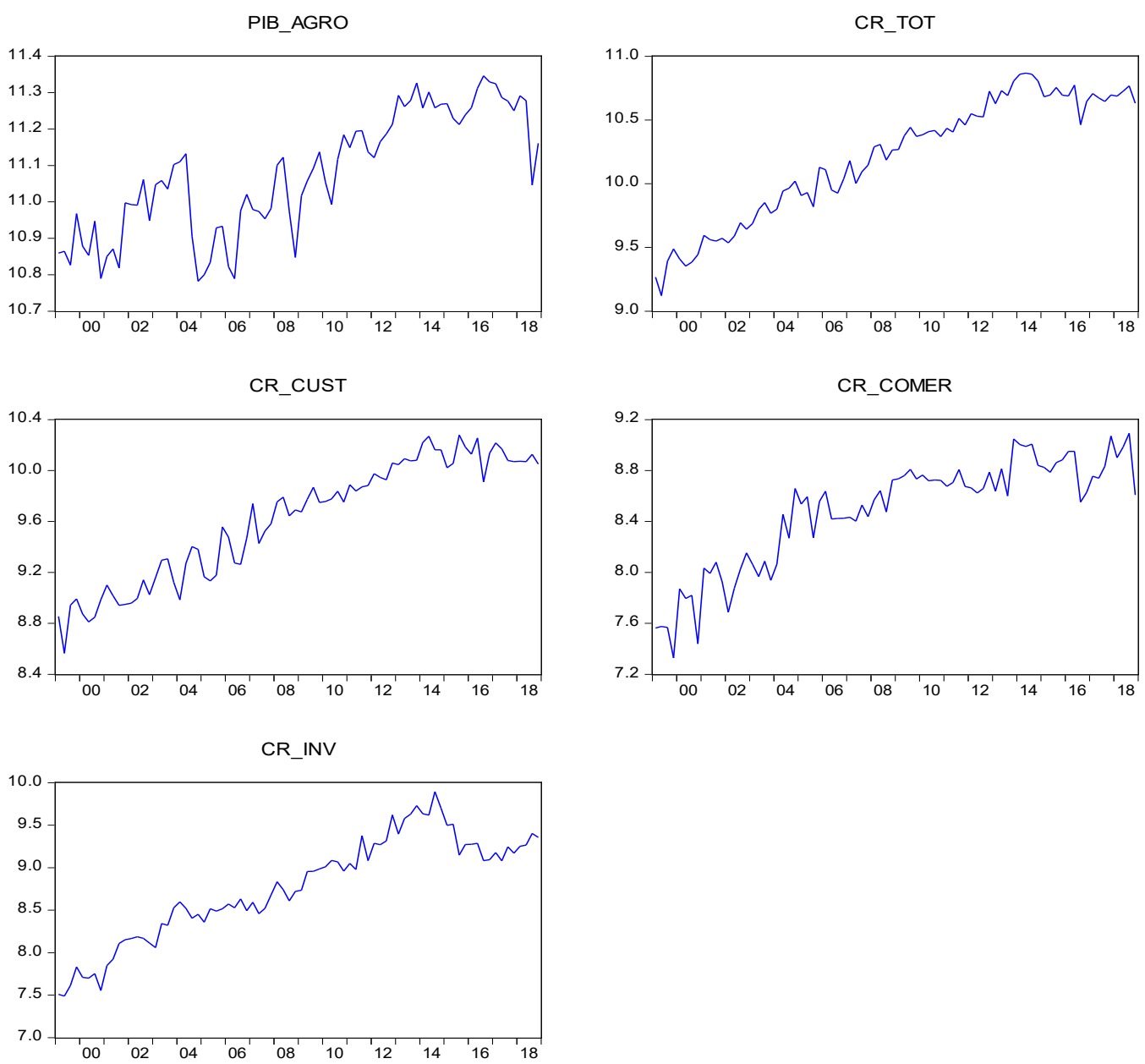

Figura 5 - Séries dessazonalizadas entre 1999 a 2018 (log). Fonte: elaborada pelo autor com base nos dados da pesquisa.

Especificamente quanto à variável $P I B_{-} A G R O$, esta apresentou elevada variabilidade entre os períodos. As altas taxas de crescimento do PIB agropecuário são registradas no primeiro

3 Para a realização da análise estatística e econométrica utilizaram-se os programas Stata ${ }^{\circledR}$ e Eviews ${ }^{\mathbb{B}}$. 
trimestre de cada ano. Ao longo do período em questão, a taxa média de crescimento do primeiro trimestre em relação ao período imediatamente anterior foi de, aproximadamente, $68 \%$.

A composição e sazonalidade da produção agrícola são as responsáveis por tais variações, conforme expresso no Relatório de Inflação Volume 19 do Banco Central do Brasil (2017). Dessa forma, as safras de soja, milho e arroz são contabilizadas, majoritariamente, no primeiro trimestre do ano. Considerando que essas culturas perderão relevância no cômputo do PIB ao longo do ano, sendo substituídas por outras com perspectiva de desempenhos inferiores, é factível esperar que a maior parte da contribuição positiva direta da safra agrícola para a atividade econômica ocorra no primeiro trimestre em detrimento dos demais períodos (Banco Central do Brasil, 2017).

Portanto, devido à época do plantio das culturas temporárias, independentemente do ano a ser considerado, o primeiro trimestre sempre é fortemente impactado pela contabilização, principalmente, das culturas de soja e milho, conforme evidenciado no comportamento da variável PIB_AGRO. Diante deste cenário, é necessário que as séries sensíveis a determinados acontecimentos ao longo de um período, como a PIB_AGRO, sejam dessazonalizadas para melhor aplicação das técnicas econométricas, conforme efetuado com as referidas variáveis e apresentada na figura 5.

Quanto à determinação da relação ótima entre produto agropecuário e crédito rural, foi desenvolvido modelo de regressão polinomial, contemplando as variáveis PIB agropecuário $\left(P I B_{-} A G R O_{i}\right)$ e crédito rural em valores nominais defasado em dois períodos $\left(C R \_T O T_{i-2}\right)$, mais um termo ao quadrado do crédito rural em valores nominais defasado em dois períodos (CR_TOT $T_{i-2}^{2}$ ). Justifica-se a utilização de dois trimestres defasados, pois as principais safras são contabilizadas no PIB agropecuário dois períodos após o seu plantio (Banco Central do Brasil, 2017).

\subsection{Modelo Econométrico}

De forma geral, os modelos VAR analisam a existência de relações lineares entre as variáveis e seus valores defasados, de forma que considerem a existência de relações de interdependência, avaliando assim o impacto dinâmico das perturbações aleatórias sobre estas variáveis (Rossi \& Neves, 2014).

Formalmente, de acordo com Enders (2015), o modelo VAR é um conjunto de equações cuja ocorrência depende do número de variáveis em que todas são igualmente tratadas como endógenas e dos seus próprios valores defasados, bem como dos valores atuais e defasados das demais variáveis. Logo, a equação geral do modelo VAR com $p$ defasagens de X e Y pode ser expressa pelas equações (1.1) e (1.2).

$$
\begin{aligned}
& X_{t}=\alpha_{0}+\sum_{i=1}^{p} a_{i} X_{t-i}+\sum_{i=1}^{p} b_{i} Y_{t-i}+\varepsilon_{1 t} \\
& Y_{t}=\alpha_{0}+\sum_{i=1}^{p} c_{i} Y_{t-i}+\sum_{i=1}^{p} d_{i} X_{t-i}+\varepsilon_{2 t}
\end{aligned}
$$

em que na equação (1.1) $X_{t}$ é a variável exógena, $X_{t-i}$ os valores da variável exógena defasados, $Y_{t-i}$ é a variável endógena incluída no modelo, $\alpha$ e $b$ os parâmetros do modelo e $\varepsilon_{l t}$ são os termos de erro estocástico. O mesmo raciocínio serve para equação (1.2), porém agora $Y_{t}$ passa a ser a variável exógena.

A especificação de um modelo VAR requer atenção com alguns pontos específicos. Primeiro, é necessária a verificação da estacionariedade das séries. Para tanto, é empregado o teste de Dickey-Fuller (Dickey \& Fuller, 1981) aumentado, que determina a ordem de integração das séries ao verificar o número de diferenças que são necessárias para tornar a série estacionária. 
Formalmente, o teste de Dickey-Fuller (Dickey \& Fuller, 1981) considera o seguinte processo autorregressivo, expresso na equação (1.3):

$y_{t}=\mu+\rho y_{t-1}+\varepsilon_{t}$

em que $\mu_{\mu}$ e $\rho$ são parâmetros e $\varepsilon_{t}$ é o resíduo. A série $y$ é estacionária se $-1<\rho<1$. Se $\quad, \quad y$ é uma série não estacionária e a variância de $y$ aumenta constantemente com o tempo e tende ao infinito.

O teste de Dickey-Fuller (Dickey \& Fuller, 1981) aumentado (ADF) utiliza esse princípio, mas enquanto o teste simples é válido apenas para séries em uma diferença, o teste aumentado é capaz de prover resultados consistentes para séries com mais de uma defasagem de diferença.

Outro teste que permite verificar a estacionariedade de uma série é o teste de Phillips e Perron - PP (Phillips \& Perron, 1988). O teste torna desnecessária a especificação de um modelo com ordem suficientemente autorregressiva para expurgar a correção serial dos resíduos (Bueno, 2015). O teste de PP possui interpretação análoga ao teste ADF, dado que as equações estimadas e os testes são praticamente idênticos. Entretanto, difere do teste ADF supondo erros correlacionados e possivelmente heteroscedásticos (Morettin, 2017).

Entretanto, um dos problemas dos testes ADF e PP é seu baixo poder, particularmente ante a presença de um componente de médias móveis perto do círculo unitário, ou seja, os referidos testes não conseguem rejeitar a hipótese nula para uma infinidade de séries econômicas (Bueno, 2015). Para tanto, foi desenvolvido o teste de Kwiatkowski-Phillips-Schmidt-Shin (KPSS). $\mathrm{O}$ teste de KPSS considera que a hipótese nula é de estacionariedade da série e pode ser formalmente representado por:

$K P S S=\sum_{t=1}^{n} \frac{S_{t}^{2}}{n^{2} \hat{v}^{2}}$

em que $\hat{v}^{2}$ é a variância de longo prazo e $S_{t}^{2}$ a soma parcial dos resíduos.

Portanto, para verificação da estacionariedade das séries estudadas, a tabela 2 apresenta as estatísticas para os testes ADF, PP e KPSS. No caso de séries não estacionárias, elas devem ser expressas em sucessivas diferenças até que seja obtida a estacionariedade. Os resultados evidenciam que as séries $P I B_{-} A G R O, C R_{-} T O T, C R_{-} C O M E R$ se mostraram I(0), estacionárias em nível, até $10 \%$ de significância, ao menos em dois dos testes realizados. $C R_{-} C U S T$ e $C R_{-} I N V$ foram não estacionárias em nível, mas tornaram-se estacionárias em primeira diferença, portanto integradas de primeira ordem, I(1).

Tabela 2 - Testes de Raiz Unitária

\begin{tabular}{|c|c|c|c|c|c|c|c|}
\hline \multirow{2}{*}{ Variável } & \multirow{2}{*}{ ADF (1) } & \multirow{2}{*}{ PP (2) } & \multicolumn{3}{|c|}{ Valor crítico a: } & \multirow{2}{*}{\multicolumn{2}{|c|}{ KPSS (3) }} \\
\hline & & & $1 \%$ & $5 \%$ & $10 \%$ & & \\
\hline PIB_AGRO & $-3,9344 * \star$ & $-3,9344 * *$ & $-4,0784$ & $-3,4677$ & $-3,1606$ & 0,1084 & * \\
\hline CR_TOT & $-2,4287$ & $-9,0784 * * *$ & $-4,0800$ & $-3,4684$ & $-3,1610$ & 0,1572 & ** \\
\hline CR_CUST & $-2,1516$ & $-4,6826 * * *$ & $-3,5203$ & $-2,9006$ & $-2,5879$ & 0,2531 & \\
\hline CR_COMER & $-4,1956 * * *$ & $-3,8908 * * *$ & $-4,0784$ & $-3,4677$ & $-3,1606$ & 0,2674 & \\
\hline CR_INV & $-2,0478$ & $-2,2723$ & $-3,5166$ & $-2,8991$ & $-2,5868$ & 0,1745 & $\star \star$ \\
\hline D(CR_CUST) & $-8,7979 * \star \star$ & $-18,1393 * * *$ & $-4,0833$ & $-3,4700$ & $-3,1619$ & 0,1158 & $\star$ \\
\hline $\mathrm{D}\left(\mathrm{CR} \_\mathrm{INV}\right)$ & $-13,0408 * \star \star$ & $-13,0583 * * *$ & $-4,0800$ & $-3,4684$ & $-3,1610$ & 0,0501 & * \\
\hline
\end{tabular}

Fonte: elaborada pelo autor com base nos dados da pesquisa. Nota: Todos os testes foram realizados com constante e tendência. (1) Dickey-Fuller Aumentado (ADF); (2) Phillips-Perron (PP); (3) Kwiatkowski-Phillips-Schmidt-Shin (KPSS). ***Nível de significância de 1\%; **Nível de significância de 5\%; *Nível de significância de 10\%. 
Além disso, com variáveis não estacionárias a análise também consistirá em observar se estas são cointegradas. A combinação de duas ou mais séries não estacionárias pode ser estacionária e, se essa combinação linear estacionária existir, diz-se que a série é cointegrada. Essa combinação pode ser interpretada como uma relação de equilíbrio de longo prazo entre as variáveis.

O procedimento é baseado no método de Johansen (1988). Será observada a presença ou não de múltiplos vetores de cointegração ao utilizar um modelo VAR como mecanismo de correção de erro, representado pelas equações (1.5) e (1.6).

$\Delta Y_{t}=\alpha_{0}+\sum_{i=1}^{n} a_{i} \Delta Y_{t-1}+\sum_{i=1}^{m} b_{i} \Delta X_{t-1}+\delta U_{t-1}+\varepsilon_{1 t}$

$\Delta X_{t}=\alpha_{0}+\sum_{i=1}^{n} c_{i} \Delta X_{t-1}+\sum_{i=1}^{m} d_{i} \Delta Y_{t-1}+\gamma V_{t-1}+\varepsilon_{2 t}$

em que $\Delta Y_{t}$ e $\Delta X_{t}$ são as variáveis em estudo nas primeiras diferenças; $U_{t-1}$ e $V_{t-1}$ são os termos de correção de erro derivados da relação de longo prazo observada entre as variáveis; e $\varepsilon_{l t}$ e $\varepsilon_{2 t}$ são os termos de erro. Dessa forma, procedeu-se o teste de cointegração de Johansen aplicado nos modelos com as variáveis estacionárias em primeira diferença, $C R \_C U S T$ e $C R_{-} I N V$, e nestes não foi evidenciada a existência de vetores de cointegração.

Outro aspecto relevante está relacionado com o número de defasagens ou ordem do VAR. Dado que comprimentos de defasagem longos podem ocasionar perda de observações por consumirem graus de liberdade, enquanto defasagens curtas geralmente estão associadas com erros de especificação, tem-se que a mitigação de tal problema se dá com a utilização de critérios de informação (Akaike, Schwarz e Hannan-Quinn), o erro de previsão final e o teste de razão verossimilhança. O método consiste em estimar um número suficiente de modelos VAR, aumentando sucessivamente o número de defasagens e depois escolher aquele que fornecer os menores valores estatísticos para os critérios de informação e para o erro de previsão final, e no caso do teste LR, a defasagem que proporciona o valor da estatística calculada maior do que seu respectivo valor crítico tabelado considerado o nível de probabilidade.

Definida a estrutura geral do modelo VAR, procede-se o teste de causalidade de Granger. No caso de as séries serem estacionárias em ordem I(0), será conduzido com as séries em nível, em que se estimam as equações (1.1) e (1.2) do modelo VAR. Caso sejam integradas de ordem um, as equações (1.1) e (1.2) utilizam as variáveis na primeira diferença. De acordo com Enders (2015), Granger propôs definições testáveis da causalidade entre duas séries de tempo, baseado no pressuposto de que a causa precede ao efeito. O teste de Granger tem como objetivo observar o quanto do valor de $Y$ observado é explicado por valores passados de $Y$ e se a adição de valores defasados de $X$ torna essa explicação melhor e mais consistente. Assim, considera-se que $Y$ é causado, no sentido de Granger, por $X$ se a variável $X$ ajuda a explicar o valor observado de $Y$, isto é, se os coeficientes das defasagens de $X$ são estatisticamente significativos.

Dessa forma, é possível definir que a variável $X_{t}$ causa $Y_{t}$, no sentido de Granger, se o erro quadrático médio (EQM) da previsão de $Y_{t}$ no instante t, com base nas informações em t-1, for menor que o EQM quando se desconsidera as informações sobre $X_{t}$. Ou seja, $X_{t}$ causa $Y_{t}$ quando as informações sobre $X_{t}$ melhorarem a previsão de $Y_{t}$.

Após realizar as estimações baseadas nas equações (1.1) e (1.2), podem-se obter quatro resultados, conforme apresentado por Gujarati (2011): 
I. Uma causalidade unidirecional de $Y_{t}$ para $X_{t}$ será indicada se os coeficientes estimados das defasagens de $Y_{t}$ forem estatisticamente diferentes de zero como grupo e o conjunto de coeficientes estimados de $X_{t}$ não forem estatisticamente diferentes de zero;

II. Uma causalidade unidirecionalde $X_{t}$ para $Y_{t}$ será indicada se os coeficientes estimados das defasagens de $Y_{t}$ não forem estatisticamente diferentes de zero e o conjunto dos coeficientes de $X_{t}$ forem estatisticamente diferentes de zero;

III. Feedback ou causalidade bilateral será sugerido quando os conjuntos de coeficientes de $Y_{t}$ e $X_{t}$ forem estatisticamente diferentes de zero em ambas as regressões;

IV. Independência quando os conjuntos de coeficientes de $Y_{t}$ e $X_{t}$ não forem estatisticamente significativos em nenhuma das regressões.

Descrita brevemente a metodologia utilizada, serão propostos quatro modelos simples neste estudo, buscando evidenciar, de forma individual, o impacto do crédito rural total e segregado por finalidade sobre o PIB agropecuário. As equações gerais de cada modelo VAR estão expressas nas equações (1.7), (1.8), (1.9) e (1.10). Cabe ressaltar que nas equações (1.8) e (1.10) a expressão ${ }^{D(\text { variável) }}$ significa que, devido à não estacionariedade em nível, as variáveis em questão estão em primeira diferença.

$$
\begin{aligned}
& P I B_{-} A G R O_{t}=\alpha_{0}+\sum_{i=1}^{p} a_{i} P I B_{-} A G R O_{t-i}+\sum_{i=1}^{p} b_{i} C R_{-} T O T_{t-i}+\varepsilon_{1 t} \\
& P I B_{-} A G R O_{t}=\alpha_{0}+\sum_{i=1}^{p} a_{i} D\left(P I B_{-} A G R O_{t-i}\right)+\sum_{i=1}^{p} b_{i} D\left(C R_{-} C U S T_{t-i}\right)+\varepsilon_{I t} \\
& P I B_{-} A G R O_{t}=\alpha_{0}+\sum_{i=1}^{p} a_{i} P I B_{-} A G R O_{t-i}+\sum_{i=1}^{p} b_{i} C R_{-} C O M E R_{t-i}+\varepsilon_{I t} \\
& P I B_{-} A G R O_{t}=\alpha_{0}+\sum_{i=1}^{p} a_{i} D\left(P I B_{-} A G R O_{t-i}\right)+\sum_{i=1}^{p} b_{i} D\left(C R_{-} I N V_{t-i}\right)+\varepsilon_{I t}
\end{aligned}
$$

Além da metodologia VAR apresentada, foi utilizado ainda neste estudo o método dos MQO e MQG para obtenção da relação ótima entre produto agropecuário e crédito rural. De acordo com Wooldridge (2016), o procedimento de MQO, conforme expresso na equação (1.12), consiste na escolha dos valores dos parâmetros desconhecidos de forma que a soma dos quadrados dos resíduos, $\Sigma \hat{\mu}_{i}^{2}$, no modelo proposto na equação (1.11), seja a menor possível.

$Y_{i}=\hat{\beta}_{1}+\hat{\beta}_{2} X_{2 i}+\hat{\beta}_{3} X_{3 i}+\hat{\mu}_{i}$

$\min \sum \hat{\mu}_{i}^{2}=\sum\left(Y_{i}-\hat{\beta}_{1}-\hat{\beta}_{2} X_{2 i}-\hat{\beta}_{3} X_{3 i}\right)^{2}$

Logo, para uma dada amostra, os parâmetros estimados por MQO são os melhores estimadores não viesados. São únicos, consistentes e com variância mínima. Por fim, na metodologia dos MQG é minimizada a soma ponderada dos quadrados dos resíduos, dado que o peso atribuído a cada observação é inversamente proporcional ao seu erro padrão, ou seja, observações vindas de uma população com erro padrão maior obterão peso relativamente menor e vice-versa. Em síntese, MQG são os MQO nas variáveis transformadas que satisfazem as hipóteses padrão de mínimos quadrados (Gujarati, 2011). O modelo polinomial estimado está expresso na equação (1.13)

$P I B_{-} A G R O_{i}=\beta_{1 i}+\beta_{2 i} C R_{-} T O T_{i-2}+\beta_{3 i} C R_{-} T O T_{i-2}^{2}+\mu_{i}$ 
Vale ressaltar ainda que os modelos polinomiais possuem alta correlação entre as variáveis independentes, mas, por seguirem uma relação não linear, não desrespeitam a hipótese de multicolinearidade. Além disso, são lineares nos parâmetros e, portanto, podem ser estimados pelo MQO (Gujarati, 2011) e, consequentemente, pelo MQG.

\section{Resultados e Discussões}

\subsection{Estimação dos Modelos VAR}

A tabela 3 apresenta os resultados dos modelos bivariados de melhor desempenho estatístico. Conforme pode ser observado, o impacto mais forte sobre PIB_AGRO entre as variáveis analisadas foi da variável $C R_{-}$TOT. Uma variação de $1 \%$ no $C R \_T O T$ causa uma variação positiva de 0,20\% no PIB_AGRO.

Tabela 3 - Efeito do crédito rural e suas finalidades sobre o PIB agropecuário

\begin{tabular}{|c|c|c|c|c|}
\hline Variável & Coeficiente & Desvio Padrão & Estatística t & p-valor \\
\hline Constante & 2,3953 & 0,8724 & 2,7454 & 0,0000 \\
\hline CR_TOT (L3) & 0,2007 & 0,0891 & 2,2524 & 0,0000 \\
\hline $\mathrm{R}^{2}$ ajustado & 0,7976 & - & - & - \\
\hline Autocorrelação & - & - & - & 0,2075 \\
\hline Normalidade & - & - & - & 0,0001 \\
\hline Heterocedasticidade & - & - & - & 0,6265 \\
\hline Constante & 2,6478 & 0,7462 & 3,5479 & 0,0000 \\
\hline CR_CUST (L1) & 0,0813 & 0,0312 & 2,6083 & 0,0000 \\
\hline $\mathrm{R}^{2}$ ajustado & 0,8024 & - & - & - \\
\hline Autocorrelação & - & - & - & 0,5517 \\
\hline Normalidade & - & - & - & 0,0001 \\
\hline Heterocedasticidade & - & - & - & 0,2064 \\
\hline Constante & 1,5924 & 0,7043 & 2,2610 & 0,0000 \\
\hline CR_COMER (L3) & 0,0652 & 0,0546 & 1,1954 & 0,0001 \\
\hline $\mathrm{R}^{2}$ ajustado & 0,8122 & - & - & - \\
\hline Autocorrelação & - & - & - & 0,1078 \\
\hline Normalidade & - & - & - & 0,0002 \\
\hline Heterocedasticidade & - & - & - & 0,4523 \\
\hline Constante & 3,2329 & 0,7947 & 4,0678 & 0,0000 \\
\hline CR_INV (L1) & 0,0769 & 0,0236 & 3,2502 & 0,0001 \\
\hline $\mathrm{R}^{2}$ ajustado & 0,8060 & - & - & - \\
\hline Autocorrelação & - & - & - & 0,3546 \\
\hline Normalidade & - & - & - & 0,0551 \\
\hline Heterocedasticidade & - & - & - & 0,1992 \\
\hline
\end{tabular}

Fonte: elaborada pelo autor com base nos dados da pesquisa. Nota: L1: defasado em um período e L3: defasado em três períodos, segundo testes para escolha do número de defasagens e de Wald para exclusão de defasagens. Os testes pós-estimação utilizados foram: teste de Breusch-Godfrey para autocorrelação, teste de Jarque-Bera para normalidade e teste de White para heterocedasticidade.

Com relação à variável $C R_{-} C U S T$, esta apresentou um coeficiente de 0,08, ou seja, uma variação de $1 \%$ no ${ }^{C} R_{-} C U S T_{\text {- }}^{-}$causa variação positiva de $0,08 \%$ no PIB_AGRO. Enquanto as variáveis $C R_{-} C O M E R$ e $C R_{-} I N V$ apresentaram menores impactos. 
Cabe ressaltar ainda que todos os modelos selecionados se mostraram homocedásticos e sem presença de autocorrelação. Conclui-se, com base na metodologia utilizada, que as elasticidades apresentadas estão em conformidade quanto aos sinais esperados, bem como aos principais trabalhos empíricos desenvolvidos acerca do tema.

\subsection{Causalidade de Granger}

A análise dos resultados prosseguiu por meio do teste de causalidade de Granger realizado para as séries PIB agropecuário e crédito rural e suas finalidades. Os resultados podem ser verificados na tabela 4.

Tabela 4 - Teste de Causalidade de Granger

\begin{tabular}{lccc}
\multicolumn{1}{c}{ Hipótese nula } & F estat. & Probabilidade & Resultado \\
PIB_AGRO não causa, no sentido de Granger, CR_TOT & 5,8627 & 0,1185 & Não rejeita \\
CR_TOT não causa, no sentido de Granger, PIB_AGRO & 8,5134 & 0,0365 & Rejeita \\
PIB_AGRO não causa, no sentido de Granger,CR_CUST & 9,4308 & 0,0241 & Rejeita \\
CR_CUST não causa, no sentido de Granger, PIB_AGRO & 14,5968 & 0,0022 & Rejeita \\
PIB_AGRO não causa, no sentido de Granger, CR_COMER & 3,8424 & 0,2790 & Não rejeita \\
CR_COMER não causa, no sentido de Granger, PIB_AGRO & 3,9527 & 0,2666 & Não rejeita \\
PIB_AGRO não causa, no sentido de Granger, CR_INV & 0,141 & 0,7073 & Não rejeita \\
CR_INV não causa, no sentido de Granger,PIB_AGRO & 10,564 & 0,0012 & Rejeita \\
\hline
\end{tabular}

Fonte: elaborada pelo autor com base nos dados da pesquisa.

A hipótese nula dos testes é que determinada variável não causa, no sentido de Granger, a variável dependente. A princípio, observa-se a rejeição da hipótese nula de que $C R \_T O T$ não causa, no sentido de Granger, o PIB_AGRO com $5 \%$ de significância. Indicando a existência de precedência temporal do crédito rural ao produto agropecuário.

Portanto, de forma unidirecional, a referida série causa, no sentido de Granger, PIB_AGRO. Utilizando-se da mesma metodologia, o estudo de Moura (2016) corrobora o resultado encontrado. Entretanto, estudos com diferentes metodologias como Melo et al. (2013) e Cavalcante (2008) apontam resultados distintos.

Observa-se também a rejeição da hipótese nula de que $C R \_I N V$ não causa, no sentido de Granger, o PIB AGRO com 1\% de significância, indicando, assim, que existe precedência temporal do crédito rural finalidade investimento ao produto agropecuário. Portanto, de forma unidirecional $C R_{-} I N V$ causa, no sentido de Granger, PIB_AGRO.

Da mesma forma rejeita-se a hipótese nula de não causalidade de Granger para as variáveis $P I B_{-} A G R O$ e CR_CUST . Entretanto, diferentemente das séries anteriores, a $5 \%$ de significância, há uma relação bidirecional entre o crédito rural na modalidade custeio e o produto agropecuário. Corrobora esse resultado o estudo de Melo et al. (2013).

Por fim, não existe precedência temporal entre ${ }^{P I B_{-} A G R O}$ e $C R_{-} C O M E R$. Logo, não se rejeita a hipótese nula de não causalidade de Granger para as referidas variáveis.

\subsection{Relação Ótima entre Produto Agropecuário e Crédito Rural}

Conforme apresentado o modelo polinomial na seção 2.2, equação (1.13), foi estimada a relação ótima entre produto agropecuário e crédito rural em valores nominais defasado em dois trimestres. Conforme pode ser observado na tabela 5, no primeiro método de 
estimação, utilizando-se de MQO, todos os coeficientes foram estatisticamente significativos, com elevado poder explicativo, com resíduos normais e heterocedásticos. Quanto à autocorrelação, os testes apresentaram divergência. A estatística $d$ de Durbin-Watson indicou ausência de autocorrelação dos resíduos, enquanto o teste de Breusch-Godfrey indicou o contrário.

Tabela 5 - Resultado das estimações do Modelo Polinomial

\begin{tabular}{|c|c|c|c|c|c|c|}
\hline \multirow{3}{*}{$\begin{array}{c}\text { Variável / } \\
\text { Testes }\end{array}$} & \multicolumn{6}{|c|}{ Método de Estimação } \\
\hline & \multicolumn{2}{|c|}{ I) MQO } & \multicolumn{2}{|c|}{ II) MQO-Quantílica* } & \multicolumn{2}{|c|}{ III) MQG** } \\
\hline & Coeficiente & p-valor & Coeficiente & p-valor & Coeficiente & p-valor \\
\hline CR & 2,206 & 0,000 & 2,381 & 0,000 & 1,987 & 0,000 \\
\hline $\mathrm{CR}^{2}$ & $-0,018$ & 0,001 & $-0,020$ & 0,060 & $-0,012$ & 0,066 \\
\hline Constante & 8,833 & 0,001 & 8,303 & 0,104 & 9,528 & 0,000 \\
\hline Observações & 78 & - & 78 & - & 78 & - \\
\hline $\mathrm{R}^{2}$ & 0,7518 & - & 0,5379 & - & 0,8487 & - \\
\hline Teste F & 113,59 & 0,000 & - & - & 223,82 & 0,000 \\
\hline Jarque-Bera & 0,520 & 0,770 & 1,646 & 0,439 & 4,158 & 0,125 \\
\hline Durbin-Watson & 2,306 & - & - & - & 1,945 & - \\
\hline Breusch-Godfrey & 2,825 & 0,092 & - & - & & \\
\hline White & 30,37 & 0,000 & - & - & - & - \\
\hline
\end{tabular}

Fonte: elaborada pelo autor com base nos dados da pesquisa. *Modelo de regressão quantílica para correção à heterocedasticidade. **Modelo de mínimos quadrados generalizados (MQG) para correção de heterocedasticidade e autocorrelação. Os testes pós-estimação utilizados foram: teste de Jarque-Bera para normalidade dos resíduos, teste de Durbin-Watson e de Breusch-Godfrey para autocorrelação e teste de White para heterocedasticidade.

Para correção dos problemas de heterocedasticidade e autocorrelação, estimaram-se outros dois métodos. Considerando o teste de Durbin-Watson válido, no segundo método estimado utilizou-se da metodologia da regressão quantílica para correção de heterocedasticidade (Koenker \& Bassett, 1978; Koenker, 2005). Neste método, por meio de MQO, estima-se a distribuição da variável dependente fazendo as regressões considerando diferentes quartis, já que estas estatísticas, em relação à média, são menos sensíveis a outliers. Por parcimônia, utilizou-se a mediana como estatística para correção da heterocedasticidade. Dessa forma, foram encontrados coeficientes mais parcimoniosos, estatisticamente significativos, razoável poder explicativo e resíduos normais, homocedásticos e com ausência de autocorrelação serial.

Por fim, considerando como válido o teste de Breusch-Godfrey, estimou-se o terceiro método para correção de heterocedasticidade e autocorrelação serial. Para tanto, utilizou-se da metodologia dos mínimos quadrados generalizados (MQG). Assim, foram encontrados coeficientes estatisticamente significativos com elevado poder explicativo e resíduos normais, homocedásticos e com ausência de autocorrelação serial.

A figura 6 apresenta os principais valores trimestrais observados da série crédito rural, bem como os valores estimados da variável crédito rural que otimizam o produto agropecuário, conforme o respectivo método utilizado. Assim, com significância estatística de $1 \%$ nas variáveis consideradas, o nível ótimo do crédito rural em bilhões de reais ao trimestre que maximiza o produto agropecuário, segundo os métodos regressão quantílica, MQO e MQG, é de, respectivamente, $R \$ 58,1, R \$ 60,7$ e $R \$ 82,5$. 


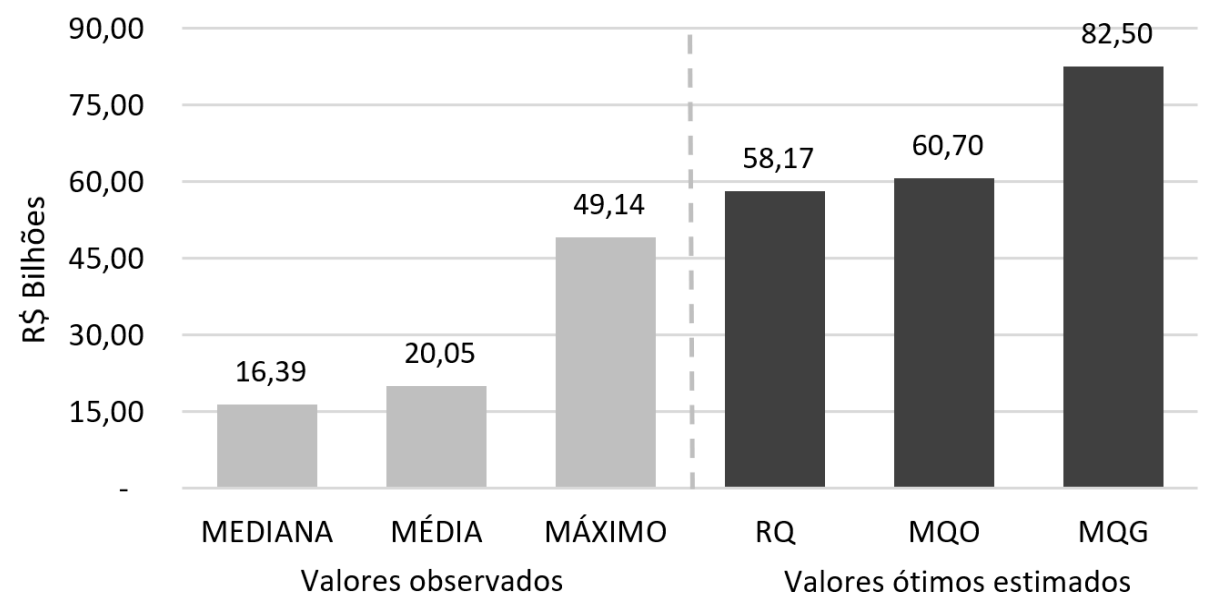

Figura 6 - Valores observados e valores ótimos estimados de crédito rural ( $\mathrm{R}$ bilhões). Fonte: elaborada pelo autor com base nos dados da pesquisa. Nota: Regressão Quantílica (RQ).

Por fim, conforme é evidenciado na figura 7, considerando o método de regressão quantílica, é apresentado o modelo polinomial mais parcimonioso de maximização do PIB agropecuário. Tais estimativas mostram que o ponto de inflexão do PIB agropecuário se dá em $\mathrm{R} \$ 70$ bilhões ao nível ótimo de crédito rural de $\mathrm{R} \$ 58$ bilhões, aproximadamente.

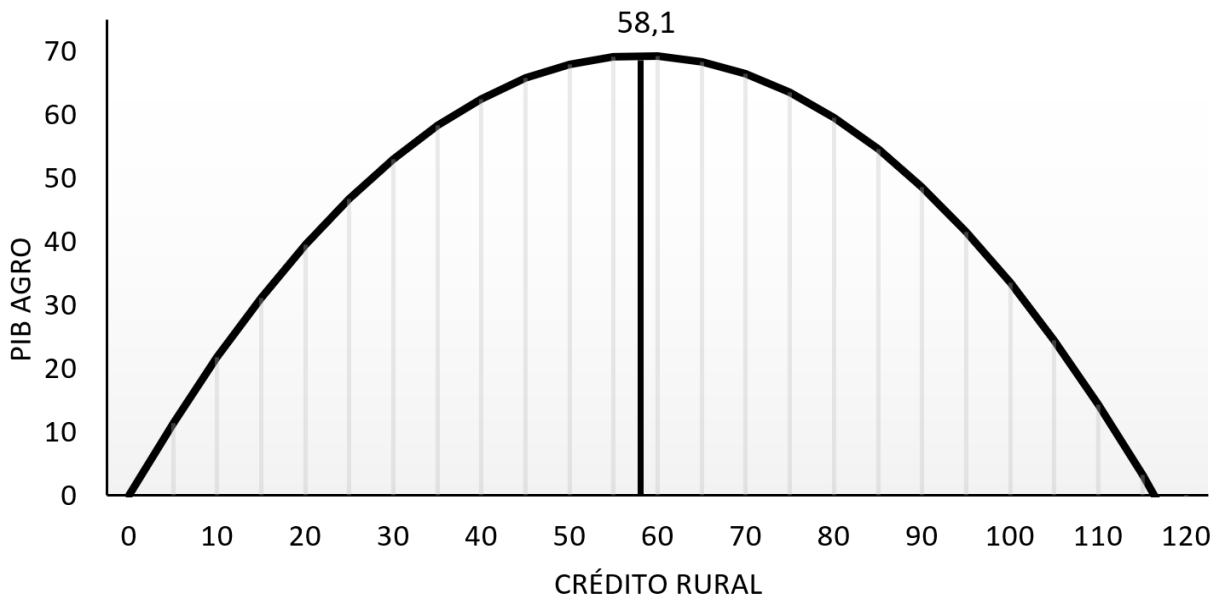

Figura 7 - Relação ótima entre produto agropecuário e crédito rural pelo modelo de regressão quantílica ( $R \$$ bilhões). Fonte: elaborada pelo autor com base nos dados da pesquisa.

Diante do que fora apresentado, pode-se concluir que todos os valores observados são menores que o nível ótimo estimado em qualquer dos métodos utilizados, que por sua vez reforça o entendimento acerca da existência de racionamento de crédito rural no país e que aumentos adicionais no volume de crédito rural concedido poderiam estimular positivamente o PIB agropecuário.

\section{Considerações Finais}

Conforme evidenciado, o crédito rural tem sido importante instrumento de política agrícola no país. Em todo período pós-Plano Real, evidencia-se sua tendência de alta mais que proporcional 
em relação ao crescimento do produto agropecuário. Verificou-se alteração nas fontes de financiamento, com redução na participação dos recursos obrigatórios em relação ao total de crédito rural disponibilizado. Observou-se ainda que a ampliação do crédito rural ocorreu de forma concentrada tanto no número de estabelecimentos rurais quanto nos contratos de valores mais elevados.

Com relação à revisão da literatura empírica, verificou-se, na maioria dos trabalhos pesquisados, a importância do crédito rural como instrumento de política agrícola para a atividade agropecuária. Diante disso, o presente trabalho visou, primeiramente, avaliar o impacto que o crédito rural total e suas modalidades produzem sobre o produto agropecuário, entre 1999 e 2018.

Constatou-se que o coeficiente do valor do produto agropecuário em relação ao valor total do crédito rural é de $0,20 \%$, o que, em tese, um aumento de $10 \%$ no volume de crédito rural disponibilizado gera, em média, um acréscimo no curto prazo de 2,07\% sobre o PIB agropecuário. Já o teste de causalidade de Granger avalia se uma variável X é importante como previsor de uma variável $Y$, mais especificamente indica se há precedência temporal entre duas variáveis. Pelo teste de causalidade de Granger constatou-se causalidade de Granger no sentido crédito rural total para o PIB agropecuário.

Em seguida, estimou-se que pelo modelo mais parcimonioso e com 1\% de significância estatística, a relação ótima entre produto agropecuário e crédito rural foi de, aproximadamente, $\mathrm{R} \$ 58$ bilhões ao trimestre. Tal valor é maior que o valor máximo registrado em todo o período analisado, $R \$ 49$ bilhões no segundo trimestre de 2016. Sugerindo, portanto, que aumentos adicionais no crédito rural poderiam estimular positivamente o PIB agropecuário e que há racionamento de crédito rural no país, conforme evidenciado por Stiglitz \& Weiss (1981), Jacob (2003) e Assunção \& Chein (2007).

Portanto, dado que a atuação do crédito rural sobre o produto agropecuário se dá pela ampliação da capacidade em adquirir insumos e capital, bem como na redução dos riscos inerentes a comercialização, ainda que exposto ao ambiente de racionamento de crédito, os resultados encontrados confirmam a hipótese de que o crédito rural impacta de forma positiva e unidirecional no produto agropecuário do país. Além disso, este trabalho está de acordo com a maioria dos estudos apresentados na síntese da literatura empírica.

Por fim, os resultados aqui obtidos podem não só servir de subsídio, mas também direcionar futuros estudos sobre o tema, principalmente na busca por séries mais longas e, consequentemente, obtenção de graus de liberdade, bem como com a inclusão, além do crédito rural, de outras variáveis explicativas que possam determinar o produto agropecuário.

\section{Referências}

Akram, W., Hussain, Z., Sabir, H. M., \& Hussain, I. (2008). Impacto of agriculture credit on growth and poverty in Pakistan. European Journal of Scientific Research, 23(2), 243-251.

Araújo, P. F. C. (2011). Política de crédito rural: reflexões sobre a experiência brasileira (Textos para Discussão CEPAL-IPEA, 37). Brasília: CEPAL: Escritório no Brasil//PEA.

Assunção, J. J., \& Chein, F. (2007). Condições de crédito no Brasil rural. Revista de Economia e Sociologia Rural. 45(2), 367-407.

Banco Central do Brasil (2017). Relatório de Inflação. Acesso em: várias datas, de tps://www. bcb.gov.br/content/ri/relatorioinflacao/201706/RELINF201706-ri201706P.pdf

Banco Central do Brasil (2019a). Anuário Estatístico de Crédito Rural. Acesso em: várias datas, de https://www.bcb.gov.br/?RELRURAL 
Banco Central do Brasil (2019b). Matriz de Dados do Crédito Rural. Acesso em: várias datas, de https://www.bcb.gov.br/pt-br/\#!/c/MICRRURAL/

Banco Central do Brasil (2019c). Manual de Crédito Rural. Acesso em: várias datas, de https:// www3.bcb.gov.br/mcr

Bacha, C. J. C. (2018). Economia e Política Agrícola no Brasil(2. ed.). São Paulo: Atlas.

Besley, T. (1994). How do market failures justify interventions in rural credit markets? The World Bank Research Observer, 9(1), 27-47.

Brasil. (1965). Lei n 4.829, de 5 de novembro de 1965. Diário Oficial [da] República Federativa do Brasil, Brasília.

Bueno, R. L. S. (2015). Econometria de Séries Temporais. (2. ed.). São Paulo: Cengage Learning.

Carrer, M. J., Souza Filho, H. M., \& Vinholis, M. M. B. (2013). Determinantes da demanda de crédito rural por pecuaristas de corte no Estado de São Paulo. Revista de Economia e Sociologia Rural, 51(3), 455-478.

Castro, E. R., \& Teixeira, E. C. (2004). Retorno dos gastos com equalização das taxas de juros do crédito rural na economia brasileira. Revista de Política Agrícola. 13(3), 52-57.

Cavalcante, I. M. (2008). Crédito Rural e Produto Agropecuário Municipal: uma análise de causalidade (Dissertação de mestrado). Faculdade de Administração, Economia e Contabilidade, Universidade de São Paulo, São Paulo.

Centro de Estudos Avançados em Economia Aplicada \& Confederação da Agricultura e Pecuária do Brasil. (2019). PIB do Agronegócio Brasileiro. Acesso em: várias datas, de https://www. cepea.esalq.usp.br/br/pib-do-agronegocio-brasileiro.aspx

Chakrabarty, T. K. (2003). Rural income: some evidence of effect of rural credit during last three decades. Reserve Bank of India Occasional Papers, 24(3), 225-39.

Dickey, D. A., \& Fuller, W. A. (1981). The Likelihood Ratio Statistics For Autoregressive Time Series With a Unit Root. Econometrica, 49(4), 1057-72.

Enders, W. (2015). Applied Econometric Time Series (4. ed.). New York: John Wiley \& Sons.

Findley, D. F., Monsell, B. C., Bell, W. R., Otto, M. C., \& Chein, B. (1998). New capabilities and methods of the X-12-ARIMA Seasonal Adjustment Program. Journal of Business \& Economic Statistics, 16(2), 127-152.

Gasques, J. G., Bacchi, M. R. P., \& Bastos, E. T. (2017). Impactos do crédito rural sobre as variáveis do agronegócio. Revista de Política Agrícola, 26(4), 132-140.

Geraldine, D. G. (2005). Economia agrícola: contribuição real no real. Revista de Economia da Universidade Estadual de Goiás. 1(1), 1-17. Acesso em: várias datas, de http://www.revista. ueg.br/index.php/economia/article/view/383/0

Guanziroli, C. E. (2019). Fronteiras de Responsabilidade do PRONAF: Lógica de Intervenção, Avaliações e Sugestões de Política. Revista de Economia e Agronegócio, 17(1), 123-146.

Gujarati, D. N. (2011). Econometria básica (5. Ed.). São Paulo: Makron Books.

Hoff, K., \& Stiglitz, J. E. (1990). Imperfect information and rural credit markets-puzzles and policy perspectives. The World Bank Economic Review, 4(3), 235-250.

Instituto Brasileiro de Geografia e Estatística. (2019a). Censo Agropecuário (2006). Acesso em: várias datas, de https://ww2.ibge.gov.br/home/estatistica/economia/agropecuaria/ censoagro/2006_segunda_apuracao/default.shtm

Instituto Brasileiro de Geografia e Estatística. (2019b). Censo Agropecuário (2017). Acesso em: várias datas, de https://censos.ibge.gov.br/agro/2017/ 
Instituto de Pesquisa Econômica Aplicada. (2019a). PIB a preços de mercado - referência 2010 (anual). Dados macroeconômicos. Acesso em: várias datas, de http://www.ipeadata.gov.br/ Instituto de Pesquisa Econômica Aplicada. (2019b). Inflação: IGP-DI (anual). Dados macroeconômicos. Acesso em: várias datas, de http://www.ipeadata.gov.br/

Jacob, C. A. (2003). Crédito Bancário no Brasil: uma interpretação heterodoxa(Tese de doutorado). Instituto de Economia/IE. Campinas/SP.154,.

Johansen, S. (1988). Statistical analysis of cointegration vectors. Journal of Economic Dynamics and Control, 12(2), 231-54.

Koenker, R., \& Bassett, G. J. (1978). Regression Quantiles. Econometrica, 46(1), 33-50.

Koenker, R. (2005). Quantile Regression (1. ed.). Cambridge: Cambridge University Press.

Melo, M. M., Marinho, E. L., \& Silva, A. B. (2013). O impulso do crédito rural no produto do setor primário brasileiro. Nexos Econômicos, 7(1), 9-35.

Morettin, P. A. (2017). Econometria financeira: um curso em séries temporais financeiras (3. ed.). São Paulo: Blucher.

Moura, F. R. (2016). O nexo causal entre crédito rural e crescimento do produto agropecuário na economia brasileira (Tese de doutorado). Escola Superior de Agricultura Luiz Queiroz. Acesso em: várias datas, de http://www.teses.usp.br/teses/disponiveis/11/11132/tde22062016-163722/en.php.

Phillips, P. C. B., \& Perron, P. (1988). Testing for a Unit Root in Time Series Regression. Biometrika, 75(2), 335-46.

Ramos, S. Y., \& Martha Junior, G. B. (2010). Evolução da política do crédito rural brasileira. Embrapa Cerrados, Planaltina. DF. Acesso em: várias datas, de https://www.embrapa.br/ busca-de-publicacoes/-/publicacao/899862/evolucao-da-politica-de-credito-rural-brasileira

Rausser, G. (1992). Predatory Versus Productive Government: the case of U.S. Agricultural Policies. Journal of Economic Perspectives, 6(3), 133-157.

Rossi, J. W., \& Neves, C. (2014). Econometria e séries temporais com aplicações a dados da economia brasileira. Rio de Janeiro: LTC.

Stiglitz, J., \& Weiss, A. (1981). Credit Rationing in Markets with Imperfect Information. American Economic Rewiew, 73(3), 333-421.

Taylor, L. (1994). Income distribution, inflation and growth (pp. 183-196.). Cambridge,Massachusets: The MIT Press.

Townsend, R. M. (1979). Optimal contracts and competitive markets with costly state verification. Journal of Economic Theory, 21(2), 265-293.

Yaron, J. (1992). Successful rural finance institutions (Discussion Paper 150). Washington, DC: World Bank.

Wooldridge, J. M. (2016). Introdução à econometria: uma abordagem moderna (6. ed.). São Paulo: Cengage Learning.

Von Pischke, J., Heffernan, D., \& Adams, W. (1981). The political economy of specialized farm credit institutions in low income countries (Staff Working Paper No. 446). Washington, DC: World Bank. 